
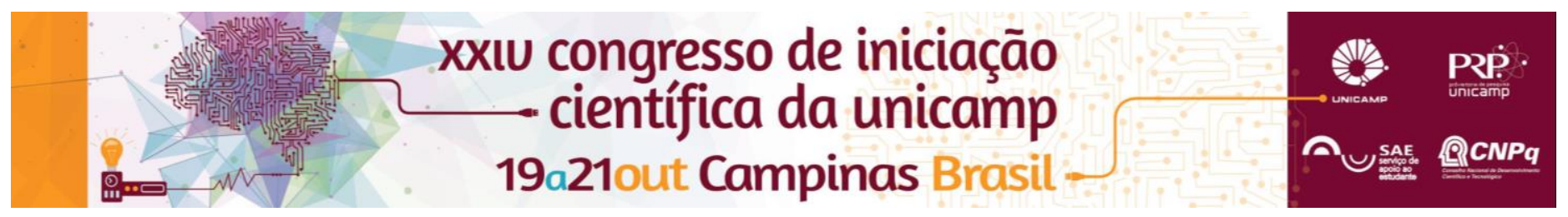

\title{
Avaliação de organogéis de óleo de soja estruturados com fitoesteróis, monoestearato de sorbitana e óleo de soja totalmente hidrogenado
}

\section{Giulia Isabela Magossi, Kamila Ramponi Rodrigues de Godoi, Ana Paula Badan Ribeiro}

\section{Resumo}

O trabalho apresentado visou obter e caracterizar organogéis isentos de ácidos graxos trans e com baixos teores de ácidos graxos saturados, através da incorporação de agentes estruturantes ao óleo de soja; além de investigar o efeito combinado da mistura de fitoesteróis livres (FL), monoestearato de sobitana (SMS) e óleo de soja totalmente hidrogenado (OSTH) como potenciais estruturantes do óleo de soja como sistema lipídico.

\section{Palavras-chave:}

Organogéis, óleo de soja, estruturantes

\section{Introdução}

As questões controversas acerca do papel dos ácidos graxos trans e aumento substancial do consumo de ácidos graxos saturados induziram nos últimos anos, diversas modificações na legislação, visando a inclusão de maiores informações para os consumidores. Dessa forma, este trabalho teve como objetivo obter e caracterizar organogéis zero trans com teores reduzidos de ácidos graxos saturados como base lipídica alternativa para aplicação em alimentos. Os organogéis são materiais viscoelásticos, onde uma fase oleosa é imobilizada por uma rede tridimensional auto-sustentada do estruturante (Dassanayake et al., 2011). Para tal objetivo utilizou-se óleo de soja, como fase lipídica contínua e FL, SMS e OSTH como agentes estruturantes.

\section{Resultados e Discussão}

A partir da definição da concentração total de estruturantes igual a $6 \%$ em relação à fase lipídica, os bons resultados obtidos com tais componentes para a formação de organogéis estáveis direcionaram o delineamento experimental para o estudo de um sistema ternário. As amostras de organogéis formulados foram caracterizadas em relação a consistência e microestrutura.

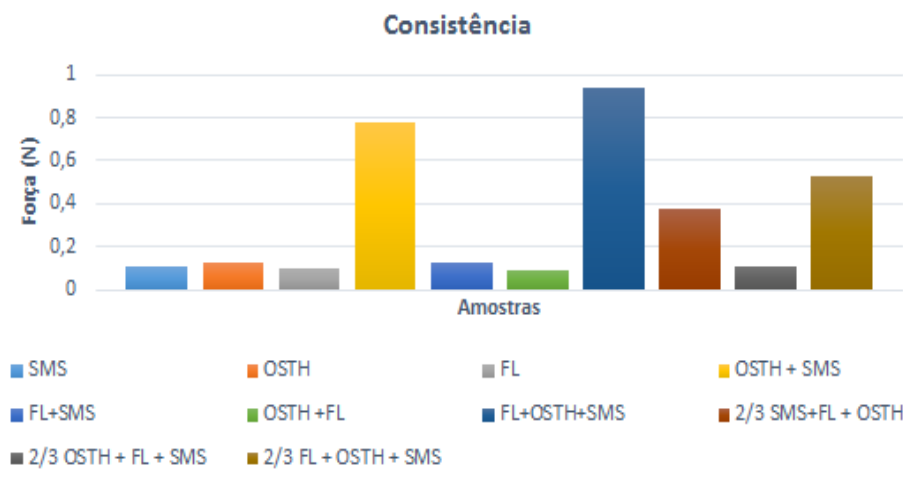

Figura 1. Resultados de consistência/compressão utilizando probe cilíndrico.

Os estruturantes incorporados isoladamente em concentração de $6 \%$ na análise de consistência com probe cilíndrico não resultaram em organogéis, caracterizando amostras totalmente líquidas. Nas misturas binárias, obteve-se bons resultados com a amostra contendo OSTH e SMS de estruturantes, com consistência mensurável média de $0,78 \mathrm{~N}$. Os resultados indicaram ausência de sinergismo entre FL e SMS devido as baixas forças de compressão. Nas amostras com os três estruturantes verificou-se resultados promissores em duas amostras: 1/3 SMS, 1/3 FL, 1/3 OSTH e 2/3FL, 1/6OSTH, 1/6 SMS.

$\mathrm{Na}$ análise de microestrutura observou-se, claramente as diferenças nos mecanismos de estruturação de cada estruturante, isoladamente, e nas respectivas misturas binária e ternária através do apecto visual da morfologia, dimensões, distribuição dos cristais e relação espacial dos mesmos. Notou-se que o OSTH apresenta estrutura de esferulito, a qual sofre redução na presença de outros estruturantes, o FL se encontra na forma de agulha e o SMS como estruturas de pequeno diâmetro, arredondadas e bem distribuídas.
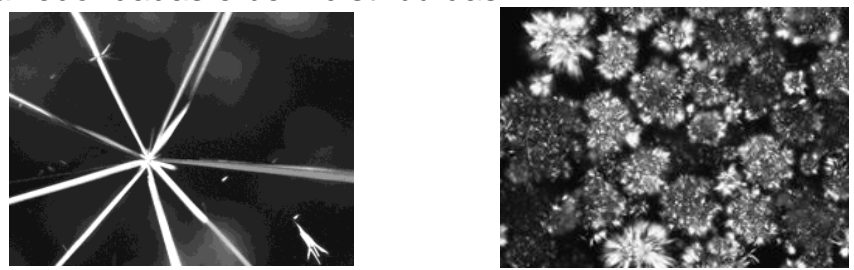

Figura 2. Amostra - 2/3 FL;1/6OSTH;1/6 SMS e amostra 1-OSTH

\section{Conclusões}

Foram obtidos organogéis firmes e estáveis, com concentração máxima de elementos estruturantes igual a $6 \%$. A interação positiva entre estruturantes do tipo partícula cristalina e self-assembly mostrou-se promissora. De acordo com a avaliação de consistência, foi possível verificar a grande influência do OSTH na estruturação das amostras e sua interação positiva com SMS, elevando o valor da força de ruptura dos géis. Observou-se ineficácia dos estruturantes incorporados isoladamente para a formação dos organogéis, bem como ausência de interação entre FL e SMS. A avaliação de microestrutura mostrou que podem ser obtidos organogéis com uma rede heterogênea de elementos estruturantes, característica relacionada principalmente à presença dos fitoesteróis.

\section{Agradecimentos}

Á Fundação de Amparo à Pesquisa do Estado de São Paulo (FAPESP) - Processo: 15/09171-8.

DASSANAYAKE, L. S. K.; KODALI, D.R.; UENO, S. Formation of oleogels based on edible lipid materials. Current Opinion in Colloid \& Interface

Science, v.16, p.432-439, 2011. 